\title{
Molecular surveillance of hepatitis $C$ virus genotypes identifies the emergence of a genotype 4d lineage among men in Quebec, 2001-2017
}

\section{DG Murphy ${ }^{1 *}, \mathrm{R}$ Dion $^{1,2}, \mathrm{M}$ Simard ${ }^{3}, \mathrm{ML}$ Vachon $^{4}, \mathrm{~V}$ Martel-Laferrière ${ }^{5}, \mathrm{~B}$ Serhir ${ }^{1}, \mathrm{~J}$ Longtin $^{1}$}

\section{Abstract}

Background: Molecular phylogenetics are generally used to confirm hepatitis $\mathrm{C}$ virus (HCV) transmission events. In addition, the Laboratoire de santé publique du Québec (LSPQ) has been using molecular phylogenetics for surveillance of HCV genotyping since November 2001.

Objectives: To describe the emergence of a specific lineage of HCV genotype 4d (G4d) and its characteristics using molecular phylogenetics as a surveillance tool for identifying $\mathrm{HCV}$ strain clustering.

Methods: The LSPQ prospectively applied Sanger sequencing and phylogenetic analysis to determine the HCV genotype on samples collected from November 2001 to December 2017. When a major G4d cluster was identified, demographic information, HIV-infection status and syphilis test results were analyzed.

Results: Phylogenetic analyses performed on approximately 22,000 cases identified $122 \mathrm{G} 4 \mathrm{~d}$ cases. One major G4d cluster composed of 37 cases was singled out. Two cases were identified in 2010, 10 from 2011-2014 and 25 from 2015-2017. Cases in the cluster were concentrated in two urban health regions. Compared to the other $\mathrm{G} 4 \mathrm{~d}$ cases, cluster cases were all male $(p<0.001)$ and more likely to be HIV-positive (adjusted risk ratio: $4.4 ; 95 \%$ confidence interval: 2.5-7.9). A positive syphilis test result was observed for 27 (73\%) of the cluster cases. The sequences in this cluster and of four outlier cases were located on the same monophyletic lineage as G4d sequences reported in HIV-positive men who have sex with men (MSM) in Europe.

Conclusion: Molecular phylogenetics enabled the identification and surveillance of ongoing transmission of a specific HCV G4d lineage in HIV-positive and HIV-negative men in Quebec and its cross-continental spread. This information can orient intervention strategies to avoid transmission of HCV in MSM.
This work is licensed under a Creative Commons Attribution 4.0 International License.

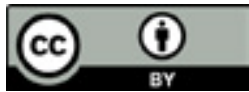

Affiliations

1 Institut national de santé publique du Québec, Laboratoire de santé publique du Québec, Sainte-Anne-de-Bellevue, OC

2 École de santé publique de I'Université de Montréal, Département de médecine sociale et préventive, Montréal, QC

${ }^{3}$ Institut national de santé publique du Québec, Bureau d'information et d'études en santé des populations, Québec, QC

${ }^{4}$ Centre hospitalier de I'Université Laval, Québec, QC

${ }^{5}$ Centre de recherche du Centre hospitalier de I'Université de Montréal, Montréal, QC

\section{*Correspondence:}

donald.murphy@inspq.qc.ca

Suggested citation: Murphy DG, Dion R, Simard M, Vachon ML, Martel-Laferrière V, Serhir B, Longtin J. Molecular surveillance of hepatitis $C$ virus genotypes identifies the emergence of a genotype $4 d$ lineage among men in Quebec, 2001-2017. Can Commun Dis Rep 2019;45(9):230-7. https://doi.org/10.4745/ccdr.v45i09a02 Keywords: HCV, genotype, G4d, surveillance, phylogenetic analyses, cluster, molecular epidemiology, men who have sex with men, MSM

\section{Introduction}

Hepatitis $\mathrm{C}$ virus $(\mathrm{HCV})$ affects 70 million people worldwide and is a major public health concern. In Canada, nearly 250,000 persons, or $0.7 \%$ of the population, are estimated to be chronically infected with $\mathrm{HCV}$ and up to $44 \%$ of this population may be unaware of their status (1). In Quebec, 1,027 cases of $\mathrm{HCV}$ were reported in 2017 (incidence rate [IR] of newly reported cases of 12.2 per 100,000 population), with a projection estimate of 1,312 cases (IR of 15.5 per 100,000 population) for 2018 (2). 
Based on prospective cohorts such as SurvUDI network and the Engage study, people who inject drugs and men who have sex with men (MSM) are disproportionally affected by HCV infection compared to the general population $(2,3)$. Chronic HCV infection, if untreated, can result in fibrosis, cirrhosis, liver failure and hepatocellular carcinoma. Early identification of HCV infection followed by treatment is crucial in reducing HCV transmission, associated morbidity and mortality and health care costs (4).

$\mathrm{HCV}$ is mostly transmitted by the parenteral route, the most common risk factors being injection drug use and blood or blood product transfusion (prior to the introduction of blood donor screening). Sexual transmission of HCV is less common, but possible. Recent data indicates an increase in $\mathrm{HCV}$ prevalence among MSM, especially among those coinfected with HIV (5). High-risk behaviours, including unprotected sex, have been identified as determinants for HCV transmission. Ulcerative sexually transmitted infections, such as syphilis, has also been associated with increased risk of HCV acquisition in $\operatorname{MSM}(6,7)$.

$\mathrm{HCV}$ is currently classified into eight genotypes (8). Genotypes are further divided into subtypes, of which 89 have been confirmed (8). At the Laboratoire de santé publique du Québec (LSPQ), Institut national de santé publique du Québec, HCV genotyping has been performed routinely since November 2001 for patient management, as genotyping helps to guide antiviral treatment of chronic infection.

Genotyping performed by sequencing analysis not only informs optimal treatment choice, it can also be a powerful molecular surveillance tool for identification of circulating virus strains. Although molecular phylogenetics cannot determine the time of infection acquisition, it can detect transmission clusters. The laboratory can then notify public health authorities that a particular HCV strain is spreading in the population $(9,10)$.

Molecular phylogenetics has not been used extensively for ongoing prospective surveillance, but studies have shown it to be a potentially useful tool. For example, nucleic acid sequencing and phylogenetic analysis have been used to identify and confirm HCV transmission events in the health care setting and to characterize transmission dynamics in the community (11-18). Phylogenetic strain clustering has also been used to investigate HCV transmission networks among HIV-infected MSM $(19,20)$. A recent study supported the feasibility of applying nucleic acid sequencing and phylogenetics to identify recent HCV transmission clusters in individuals with unknown histories of transmission (21).

The objective of this article is to describe the use of molecular sequencing and phylogenetics as a tool for prospective surveillance of HCV transmission at the population level. Namely, we show how this approach identified the emergence and ongoing transmission of HCV genotype 4d (G4d) among
HIV-positive and HIV-negative men in Quebec and how we were able to identify its source.

\section{Methods}

\section{Study population}

In Quebec, HCV genotyping is conducted at the LSPQ. Samples submitted for routine HCV genotyping from November 13, 2001 to December 31, 2017 were included in this study. Samples were submitted from hospital laboratories and public or private clinics in Quebec. Data on the G4d cases originated from the LSPQ's laboratory information system and included basic demographic information (age, sex, health region of residence), date of specimen collection and test results for HIV and syphilis infections. These were retrieved from the information system using patients' unique identifier numbers. Data on exposures or risk factors were not collected. Genotype results are not routinely reported to the public health regional authorities.

\section{Genotyping and nucleotide sequence analysis}

The HCV genotype of each sample was assessed as it was received. Most samples were received within 30 days of blood collection. Viral ribonucleic acid (RNA) extraction from serum or plasma as well as reverse transcription polymerase chain reaction (RT-PCR), DNA sequencing and genotyping based on nonstructural protein $5 B$ (NS5B) sequences were performed as previously described (22). Quebec's G4d sequences were compared to sequences previously reported in HIV-infected MSM in the Netherlands and France (23-25). To compare Quebec's G4d sequences with those reported in the van de Laar et al. study (20) for participants from England, France, Germany and the Netherlands, the corresponding NS5B nucleotide sequence was obtained for a subset of Quebec's G4d isolates by use of reverse primer DM503 (5'-CCACGCTCTCAACGGTGGTAC-3) and forward primer DM101 to generate a 805 base pair sequence fragment (22). These were selected on the basis of sample availability. Phylogenies were estimated by the neighbour-joining method according to the maximum composite likelihood model of nucleotide substitution implemented in Molecular Evolutionary Genetic Analysis (MEGA) software version 6 (26). As many as 1,000 bootstrap replicates were performed to evaluate the robustness of the phylogeny. Sequences were considered to be part of a cluster if the following three criteria were met: showed less than $3 \%$ nucleotide difference; displayed a bootstrap support value of greater than 70\%; and consisted of at least three cases. The closeness of cases in terms of time and space was not included in this definition. G4d sequences for isolates reported in this study were submitted to GenBank and can be retrieved under accession numbers MK950000 to MK950149. NS5B sequences for isolates 3_QC55 (EF116095), 10_QC307 (EF116147), and 27_QC382 (FJ462437) were submitted previously to GenBank. 


\section{Statistical analysis}

Descriptive analysis of the data was conducted using Epi Info software version 7.2.2.6 (27) and statistical package SAS version 9.3 (28). This analysis was based on specimen collection dates, grouped as quarterly periods. For univariate analysis, statistical comparisons of categorical variables (age group, sex, health region, G4d HCV cluster and HIV infection status) were performed using bilateral Mantel-Haenszel chi square test and modified Poisson regression with a robust error variance sandwich estimation (29). To assess their link with cluster A outcome, the multivariate analysis using robust Poisson regression included the following independent variables in the model: HIV infection (yes versus no or unknown) and age group (50 years or older vs younger than 50 years). Given that none of the cluster A cases were female, this analysis was restricted to males. Statistically significant levels for confidence intervals $(\mathrm{Cl})$ of risk ratio (RR) estimates and bilateral $p$ values were set at $5 \%$.

\section{Results}

From November 13, 2001 to December 31, 2017, HCV genotypes were determined from a total of approximately 22,000 cases. $\mathrm{G} 1$ was the most prevalent genotype $(59.7 \%)$, followed by G3 (25.7\%), G2 (8.6\%), G4 (3.8\%), G6 (1.6\%), G5 (0.6\%) and G7 (0.01\% [three cases only]). Phylogenetic analyses of NS5B sequences revealed notable clusters mainly among genotypes $1 \mathrm{a}, 1 \mathrm{~b}, 2 \mathrm{~b}, 3 \mathrm{a}$ and $4 \mathrm{~d}$. One major $\mathrm{G} 4 \mathrm{~d}$ cluster composed of 37 cases was singled out and is described in this study.

Overall, G4 was found in 834 cases. Five G4 cases displayed low levels of viremia and the genotype was determined based on the $5^{\prime}$ UTR (5' untranslated region) sequence, which is too conserved for subtype determination. G4d was found in 122 (14.7\%) of $829 \mathrm{G} 4$ cases for which the subtype was available.

\section{Strain clustering of G4d cases}

The first G4d case was recorded in December 2001 (Figure 1). From 2002 to 2014, an average of six cases per year was observed. In 2015, 16 cases were noted. This increase continued

Figure 1: Number of hepatitis $C$ virus genotype $4 d$ cases by year and quarter of specimen collection and sequence clusters, November 2001 to December 2017, Quebec, Canada

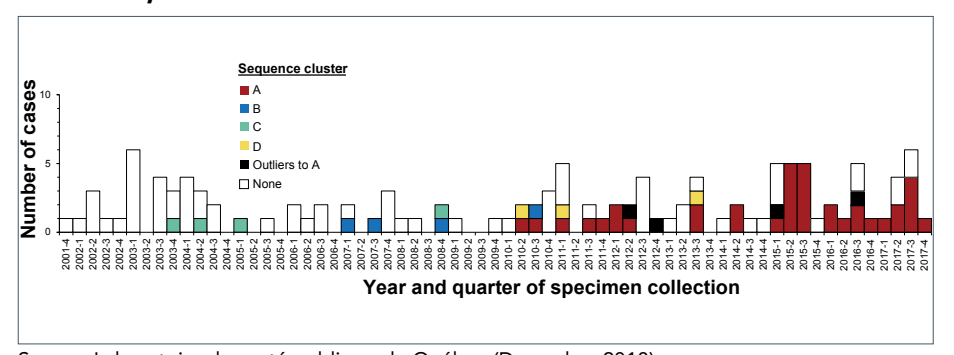

Source: Laboratoire de santé publique du Québec (December 2018) throughout 2016 and 2017. A phylogenetic tree was constructed based on NS5B sequences for the $122 \mathrm{G} 4 \mathrm{~d}$ cases and analyzed for strain clustering. Four G4d clusters (named $A$ to $D$ ) were identified (Figure 1 and Figure 2). Cluster A comprised 37 cases, clusters $B$ and $C$ each comprised four cases, and cluster $D$ comprised three cases. G4d cluster A cases first appeared in the

Figure 2: Phylogenetic tree of genotype 4d NS5B hepatitis $C$ virus isolate sequences, Quebec, Canada, November 2001 to December $2017(n=122)$

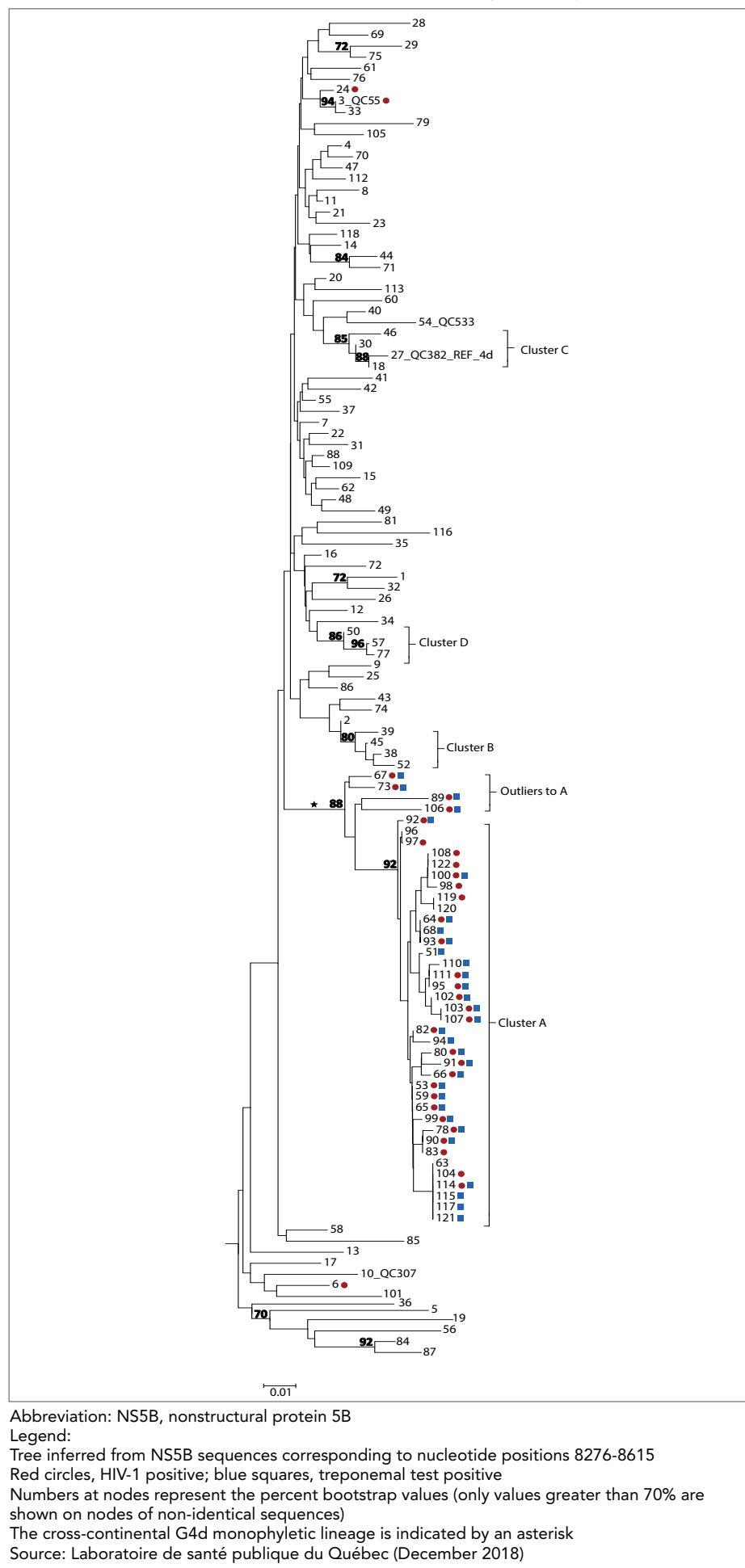


second quarter of 2010. Cases within each of clusters $B, C$ and D were scattered in time (Figure 1). An increase in cluster $A$ cases was observed from the second quarter of 2015 to the fourth quarter of 2017, for which 24 of 32 (75\%) G4d cases were part of this cluster.

Four cases (designated as outliers to cluster A) that localized on the same monophyletic lineage as cluster $A$ cases were also identified. However, these were excluded as they displayed greater than $3 \%$ nucleotide differences from cluster A strains (Figure 1 and Figure 2). Outliers to cluster $A$ cases were identified during the same period as cluster $A$ cases. Sequences of cluster $A$ and of the four outliers localized on the same monophyletic lineage as G4d sequences were reported in HIV-positive MSM in England, France, Germany and the Netherlands (Figures A1 and A2 in Appendix 1) (20,23-25).

\section{Demographics and other sexually transmitted infections}

On univariate analysis, cluster A cases, compared to the other G4d cases, were more likely to be male (100\% vs 62\%; RR: undefined; $p<0.001)$, HIV-positive (73\% vs $8 \%$; RR: $6.99 ; 95 \% \mathrm{Cl}: 3.80-12.84 ; p<0.001)$, and 50 years or older (60\% vs 34\%; RR: $2.04 ; 95 \% \mathrm{Cl}: 1.18-3.54 ; p=0.01)$. In multivariate analysis restricted to male cases, age group (adjusted RR [aRR]: 1.66; 95\% Cl: 1.11-2.50; $p=0.02$ ) and HIV infection (aRR: 4.43; 95\% Cl: 2.49-7.88; $p<0.001$ ) remained significantly associated with the cluster A outcome. Of cluster A cases, 27 (73\%) had a history of positive treponemal test results for syphilis and 20 (57\%) were both HIV-positive and had a history of positive treponemal test results.

Cluster $A$ cases resided in seven of the 18 health regions in Quebec, but were concentrated in two nonadjacent and predominantly urban regions. These two regions accounted for $78.3 \%$ of cluster A cases (Table 1). Of note, in one of the urban regions (health region $Y$ ), 14 of 24 (58.3\%) observed $G 4 d$ cases were part of cluster A. Although the IR of newly notified cases of
$\mathrm{HCV}$ in health region $\mathrm{Y}$ was fourfold lower than in health region $X$ from 2013-2017, an equivalent number of $G 4 d$ cluster $A$ cases was observed in these two health regions (14 vs 15). The cases not in cluster $A$ resided in 14 health regions, of which the one with the largest population of the province accounted for $49.4 \%$ of cases.

\section{Discussion}

In this study, we found that HCV molecular phylogenetics identified the transmission of a specific lineage (cluster $A$ ) of HCV G4d among men in Quebec; this would otherwise have remained undocumented. The $\mathrm{G} 4 \mathrm{~d}$ cluster $A$ strains were found to be concentrated in two urban health regions ( $X$ and $Y$ ) and localized on the same monophyletic lineage as $\mathrm{G} 4 \mathrm{~d}$ sequences reported in HIV-positive MSM in England, France, Germany and the Netherlands $(20,23-25)$ and later in Spain (30). Although it is likely that this particular G4d cluster A strain was introduced to Canada from Europe, the origin of this strain in Quebec remains unknown.

These findings suggest that high-risk sexual behaviour may be the mode of spread of G4d among the cluster A cases. The international transmission network of this strain in HIV-infected MSM are not injection drug users. There was also a high prevalence of positive treponemal test results. Syphilis is considered as a marker of high-risk sexual behaviour (31). Ulcerative sexually transmitted infections, such as syphilis, have been associated with increased risk of sexual HCV acquisition in $\operatorname{MSM}(6,7)$.

In 2015, the emergence of this cluster was brought to the attention of provincial public health authorities and the two regional public health authorities most affected. Since sexually active HIV-negative MSM are also at risk of HCV infection, annual $\mathrm{HCV}$ testing is recommended for MSM who engage in HIV preexposure prophylaxis (32).

Table 1: Number, proportion and mean incidence rate of hepatitis $C$ virus and number and proportion of hepatitis $C$ virus genotype $4 d$ cases among cluster $A$ and others, by health regions, Quebec

\begin{tabular}{|c|c|c|c|c|c|c|c|c|c|c|}
\hline \multirow{3}{*}{$\begin{array}{l}\text { Health } \\
\text { region }\end{array}$} & \multirow{3}{*}{$\begin{array}{l}\text { Population } \\
\text { in } 2015(n)^{a}\end{array}$} & \multicolumn{3}{|c|}{$\begin{array}{l}\text { Mean annual HCV cases, } \\
2013-2017 \text { (2) }\end{array}$} & \multicolumn{6}{|c|}{$\begin{array}{c}\text { HCV G4d cases from November } 2001 \\
\text { to December } 2017^{b}\end{array}$} \\
\hline & & \multirow{2}{*}{$\mathbf{n}$} & \multirow{2}{*}{$\%$} & \multirow{2}{*}{$\mathbf{I R}^{\mathrm{c}}$} & \multicolumn{2}{|c|}{ In cluster $\mathbf{A}$} & \multicolumn{2}{|c|}{ Not in cluster $\mathbf{A}$} & \multicolumn{2}{|c|}{ Total } \\
\hline & & & & & $\mathbf{n}$ & $\%$ & $\mathbf{n}$ & $\%$ & $\mathbf{n}$ & $\%$ \\
\hline$x$ & $1,992,106$ & 399 & 36.6 & 20.0 & 15 & 40.5 & 42 & 49.4 & 57 & 46.7 \\
\hline Y & 736,787 & 92 & 8.4 & 12.5 & 14 & 37.8 & 10 & 11.8 & 24 & 19.7 \\
\hline Others & $5,562,462$ & 600 & 55.0 & 10.8 & 8 & 21.6 & 33 & 38.8 & 41 & 33.6 \\
\hline Total & $8,291,355$ & 1,091 & 100.0 & 13.2 & 37 & 100.0 & 85 & 100.0 & 122 & 100.0 \\
\hline
\end{tabular}

Abbreviations: $\mathrm{G} 4 \mathrm{~d}$, genotype $4 \mathrm{~d}$; $\mathrm{HCV}$, hepatitis $\mathrm{C}$ virus; IR, incidence rate

a Ministère de la santé et des services sociaux du Québec, demographic estimates and projections, March 2018

b Source: Laboratoire de santé publique du Québec (December, 2018)

c Mean incidence rate of notified cases per 100,000 persons per year 
Though most cases in cluster A were coinfected with HIV, $27 \%(10 / 37)$ had no laboratory evidence of HIV infection. This indicates likely transmission from HIV-positive to HIV-negative men or vice versa. HCV strain clustering, including G4d, among HIV-positive and HIV-negative MSM has been observed in France and the Netherlands in study participants enrolled in HIV preexposure prophylaxis programs $(24,33)$.

\section{Strengths and limitations}

The main strength of this study is the high number of HCV-infected cases (about 22,000) for whom uniform sequencing results were available through the study period. An added strength was that the genotyping was performed in the same central reference laboratory. The estimated cumulative number of HCV chronic infections in Quebec reached 42,000 in 2017; nearby $75 \%$ can be assumed to be viremic (2). Thus, the number of individuals included in this study represents a significant proportion of cases who have been diagnosed and are viremic. Nevertheless, G4d cluster A cases are likely to be underestimated as some may not have been diagnosed; in addition, genotyping tests may not have been requested for all cases. Even with this underestimation, the genotyping data was probably unbiased given that it was not directed at specific subgroups of the population.

A limitation of this analysis is that there is no strict definition of strain clustering, as it varies depending on the region of the genome analyzed and the study population. In addition, the rate of HCV evolution can vary over time, based on the individual, and may impact clustering of viral strains. Also, the use of longer HCV sequences could have increased the accuracy of cluster identification (34). This study did not include data about determinants, exposures, sexual orientation or epidemiologic links between cases, and could not distinguish the mode of transmission of infection; as such, it can only provide indirect clues of HCV propagation among Quebecois men, most probably MSM.

\section{Conclusion}

Molecular phylogenetic-based surveillance revealed an ongoing transmission in Quebec of a specific cluster of HCV G4d. This cluster localized on the same monophyletic lineage as G4d sequences reported in HIV-infected MSM in several countries in Europe, indicating a cross-continental spread of this specific lineage. Phylogenetic analysis results coupled with basic demographic data produces an epidemiologic profile of HCV cases that can orient preventive interventions to avoid HCV transmission among sexually active HIV-positive and HIV-negative MSM.

\section{Authors' statement}

DGM - Conceptualization, methodology, software, data collection and conservation, validation, official analysis, writing of the first draft, display, supervision, project administration
RD - Conceptualization, methodology, software, official analysis, writing the first draft, review and revision of the final version, display

MS - Conceptualization, methodology, software, official analysis, review and revision of the final version

MLV - Clinical expertise, review and revision of the final version $\mathrm{VML}$ - Clinical expertise, review and revision of the final version BS - Data collection, review and revision of the final version $\mathrm{JL}$ - Project administration, review and revision of the final version, supervision

\section{Conflict of interest}

None.

\section{Acknowledgements}

The authors thank L Désautels, J Ménard, M Morin, A Chammat and JL Aguilar for laboratory testing of specimens and collaboration.

\section{Funding}

This work was supported by the Laboratoire de santé publique du Québec, Institut national de santé publique du Québec. The work of VML is supported by a Chercheur boursier Junior 1 award from the Fonds de recherche du Québec - Santé.

\section{References}

1. Trubnikov M, Yan $P$, Archibald C. Estimated prevalence of hepatitis $C$ virus infection in Canada, 2011. Can Commun Dis Rep 2014 Dec;40(19):429-36. DOI PubMed

2. Blouin K, Lambert G, Venne S. Portrait des infections transmissibles sexuellement et par le sang (ITSS) au Québec: année 2017 et projections 2018. Quebec (QC): Institut national de santé publique du Québec (INSPQ). 2018. pp. 61-6. https://www.inspq.qc.ca/publications/2471

3. Lambert G, Cox J, Messier-Peet M, Apelian H. EEM Moodie et les membres de l'équipe de recherche Engage. Engage Montréal. Portrait de la santé sexuelle des hommes de la région métropolitaine de Montréal ayant des relations sexuelles avec des hommes: cycle 2017-2018. Faits saillants. Quebec $(\mathrm{QC})$ : Centre intégré universitaire de santé et des services sociaux (CIUSSS) du Centre-Sud-de-l'île-deMontréal; 2019. https://www.inspq.qc.ca/sites/default/files/ documents/itss/engage_faitssaillants_mars-2019-b.pdf

4. Myers RP, Krajden M, Bilodeau M, Kaita K, Marotta P, Peltekian K, Ramji A, Estes C, Razavi H, Sherman M. Burden of disease and cost of chronic hepatitis $C$ infection in Canada. Can J Gastroenterol Hepatol 2014 May;28(5):24350. DOl PubMed 
5. Hagan H, Jordan AE, Neurer J, Cleland CM. Incidence of sexually transmitted hepatitis $C$ virus infection in HIV-positive men who have sex with men. AIDS 2015 Nov;29(17):233545. DOl PubMed

6. Vanhommerig JW, Lambers FA, Schinkel J, Geskus RB, Arends JE, van de Laar TJ, Lauw FN, Brinkman K, Gras $L$, Rijnders BJ, van der Meer JT, Prins $M$ on behalf of the MOSAIC (MSM Observational Study of Acute Infection With Hepatitis C) Study Group. Risk factors for sexual transmission of hepatitis $C$ virus among human immunodeficiency virus-infected men who have sex with men: a case-control study. Open Forum Infect Dis 2015 Aug;2(3):ofv115. DOI PubMed

7. Medland NA, Chow EP, Bradshaw CS, Read TH, Sasadeusz JJ, Fairley CK. Predictors and incidence of sexually transmitted Hepatitis $C$ virus infection in HIV positive men who have sex with men. BMC Infect Dis 2017 Mar;17(1):185. DOI PubMed

8. Smith DB, Bukh J, Kuiken C, Muerhoff AS, Rice CM, Stapleton JT, Simmonds P. HCV classification: a web resource to manage the classification and genotype and subtype assignments of hepatitis $C$ virus. International Committee on Taxonomy of Viruses (ICTV); 2013 Sep 9 (Accessed 201905-26). https://talk.ictvonline.org/ictv_wikis/flaviviridae/w/ sg_flavi/56/hcv-classification

9. Khudyakov Y. Molecular surveillance of hepatitis C. Antivir Ther 2012;17 7 Pt B:1465-70. DOl PubMed

10. Grad YH, Lipsitch M. Epidemiologic data and pathogen genome sequences: a powerful synergy for public health. Genome Biol 2014 Nov;15(11):538. DOl PubMed

11. Power JP, Lawlor E, Davidson F, Holmes EC, Yap PL, Simmonds P. Molecular epidemiology of an outbreak of infection with hepatitis $C$ virus in recipients of anti-D immunoglobulin. Lancet 1995 May;345(8959):1211-3. DOI PubMed

12. Casiraghi $M A$, De Paschale $M$, Romanò $L$, Biffi $R$, Assi A, Binelli G, Zanetti AR. Long-term outcome (35 years) of hepatitis $C$ after acquisition of infection through mini transfusions of blood given at birth. Hepatology 2004 Jan;39(1):90-6. DOI PubMed

13. Lanini S, Abbate I, Puro V, Soscia F, Albertoni F, Battisti W, Ruta A, Capobianchi MR, Ippolito G. Molecular epidemiology of a hepatitis $C$ virus epidemic in a haemodialysis unit: outbreak investigation and infection outcome. BMC Infect Dis 2010 Aug;10:257. DOI PubMed

14. Sacks-Davis R, Daraganova G, Aitken C, Higgs P, Tracy $L$, Bowden S, Jenkinson R, Rolls D, Pattison P, Robins G, Grebely J, Barry A, Hellard M. Hepatitis C virus phylogenetic clustering is associated with the social-injecting network in a cohort of people who inject drugs. PLoS One 2012;7(10):e47335. DOI PubMed
15. Jacka B, Applegate $T$, Krajden M, Olmstead A, Harrigan PR, Marshall B, DeBeck K, Milloy MJ, Lamoury F, Pybus OG, Lima VD, Magiorkinis G, Montoya V, Montaner J, Joy J, Woods C, Dobrer S, Dore GJ, Poon AF, Grebely J. Phylogenetic clustering of hepatitis $C$ virus among people who inject drugs in Vancouver, Canada. Hepatology 2014 Nov;60(5):1571-80. DOl PubMed

16. Bretaña NA, Boelen $L$, Bull R, Teutsch S, White PA, Lloyd AR, Luciani F; HITS-p investigators. Transmission of hepatitis C virus among prisoners, Australia, 2005-2012. Emerg Infect Dis 2015 May;21(5):765-74. DOI PubMed

17. Paraschiv S, Banica L, Nicolae I, Niculescu I, Abagiu A, Jipa $R$, Pineda-Peña AC, Pingarilho $M$, Neaga E, Theys K, Libin P, Otelea D, Abecasis A. Epidemic dispersion of HIV and HCV in a population of co-infected Romanian injecting drug users. PLoS One 2017 Oct;12(10):e0185866. DOI PubMed

18. Alroy-Preis S, Daly ER, Adamski C, Dionne-Odom J, Talbot EA, Gao F, Cavallo SJ, Hansen K, Mahoney JC, Metcalf E, Loring C, Bean C, Drobeniuc J, Xia GL, Kamili S, Montero JT; New Hampshire and Centers for Disease Control and Prevention Investigation Teams. Large outbreak of hepatitis $C$ virus associated with drug diversion by a healthcare technician. Clin Infect Dis 2018 Aug;67(6):845-53. DOI PubMed

19. Serpaggi J, Chaix ML, Batisse D, Dupont C, Vallet-Pichard A, Fontaine H, Viard JP, Piketty C, Rouveix E, Rouzioux C, Weiss $\mathrm{L}$, Pol S. Sexually transmitted acute infection with a clustered genotype 4 hepatitis $C$ virus in HIV-1-infected men and inefficacy of early antiviral therapy. AIDS 2006 Jan;20(2):23340. DOI PubMed

20. van de Laar T, Pybus O, Bruisten S, Brown D, Nelson M, Bhagani $S$, Vogel $M$, Baumgarten A, Chaix ML, Fisher $M$, Gotz H, Matthews GV, Neifer S, White P, Rawlinson W, Pol S, Rockstroh J, Coutinho R, Dore GJ, Dusheiko GM, Danta M. Evidence of a large, international network of HCV transmission in HIV-positive men who have sex with men. Gastroenterology 2009 May;136(5):1609-17. DOI PubMed

21. Olmstead AD, Joy JB, Montoya $V$, Luo I, Poon AF, Jacka $B$, Lamoury F, Applegate T, Montaner J, Khudyakov Y, Grebely J, Cook D, Harrigan PR, Krajden M. A molecular phylogenetics-based approach for identifying recent hepatitis C virus transmission events. Infect Genet Evol 2015 Jul;33:101-9. DOI PubMed

22. Murphy DG, Willems $B$, Deschênes $M$, Hilzenrat $N$, Mousseau R, Sabbah S. Use of sequence analysis of the NS5B region for routine genotyping of hepatitis $C$ virus with reference to $C / E 1$ and 51 untranslated region sequences. J Clin Microbiol 2007 Apr;45(4):1102-12. DOI PubMed

23. Larsen C, Chaix ML, Le Strat Y, Velter A, Gervais A, Aupérin I, Alric L, Duval X, Miailhes P, Pioche C, Pol S, Piroth L, Delarocque-Astagneau E. steering committee of the HEPAIG study. Gaining insight into HCV emergence in HIV-infected men who have sex with men: the HEPAIG Study. PLoS One 2011;6(12):e29322. DOI PubMed 
31. Burchell AN, Gardner SL, Mazzulli T, Manno M, Raboud J, Allen VG, Bayoumi AM, Kaul R, McGee F, Millson P, Remis RS, Wobeser W, Cooper C, Rourke SB. Hepatitis C virus seroconversion among HIV-positive men who have sex with men with no history of injection drug use: results from a clinical HIV cohort. Can J Infect Dis Med Microbiol 2015 Jan-Feb;26(1):17-22. DOI PubMed

32. Ministère de la santé et des services sociaux du Québec.La prophylaxie préexposition au virus de l'immunodéficience humaine: guide pour les professionnels de la santé du Québec. Quebec (QC): MSSS; 2019.

http://publications.msss.gouv.qc.ca/msss/document-000313/

33. Hoornenborg E, Achterbergh RC, Schim van der Loeff MF, Davidovich U, Hogewoning A, de Vries HJ, Schinkel J, Prins $M$, van de Laar TJ; Amsterdam PrEP Project team in the HIV Transmission Elimination AMsterdam Initiative, MOSAIC study group. MSM starting preexposure prophylaxis are at risk of hepatitis C virus infection. AIDS 2017 Jul;31(11):160310. DOI PubMed

34. Lamoury FM, Jacka B, Bartlett $S$, Bull RA, Wong A, Amin J, Schinkel J, Poon AF, Matthews GV, Grebely J, Dore GJ, Applegate TL. The influence of hepatitis $C$ virus genetic region on phylogenetic clustering analysis. PLoS One 2015 Jul;10(7):e0131437. DOl PubMed

30. Caro-Pérez N, Martínez-Rebollar M, Gregori J, Quer J, González P, Gambato M, García-González N, González-Candelas F, Costa J, Esteban JI, Mallolas J, Forns X, Laguno M, Pérez-Del-Pulgar S. Phylogenetic analysis of an epidemic outbreak of acute hepatitis $C$ in HIV-infected patients by ultra-deep pyrosequencing. J Clin Virol 2017 Jul;92:42-7. DOI PubMed 


\section{Appendix: Supplementary data}

Figure A1: Phylogenetic tree of genotype 4d NS5B hepatitis $C$ virus isolate sequences: cases in Quebec compared to cases in France and the Netherlands

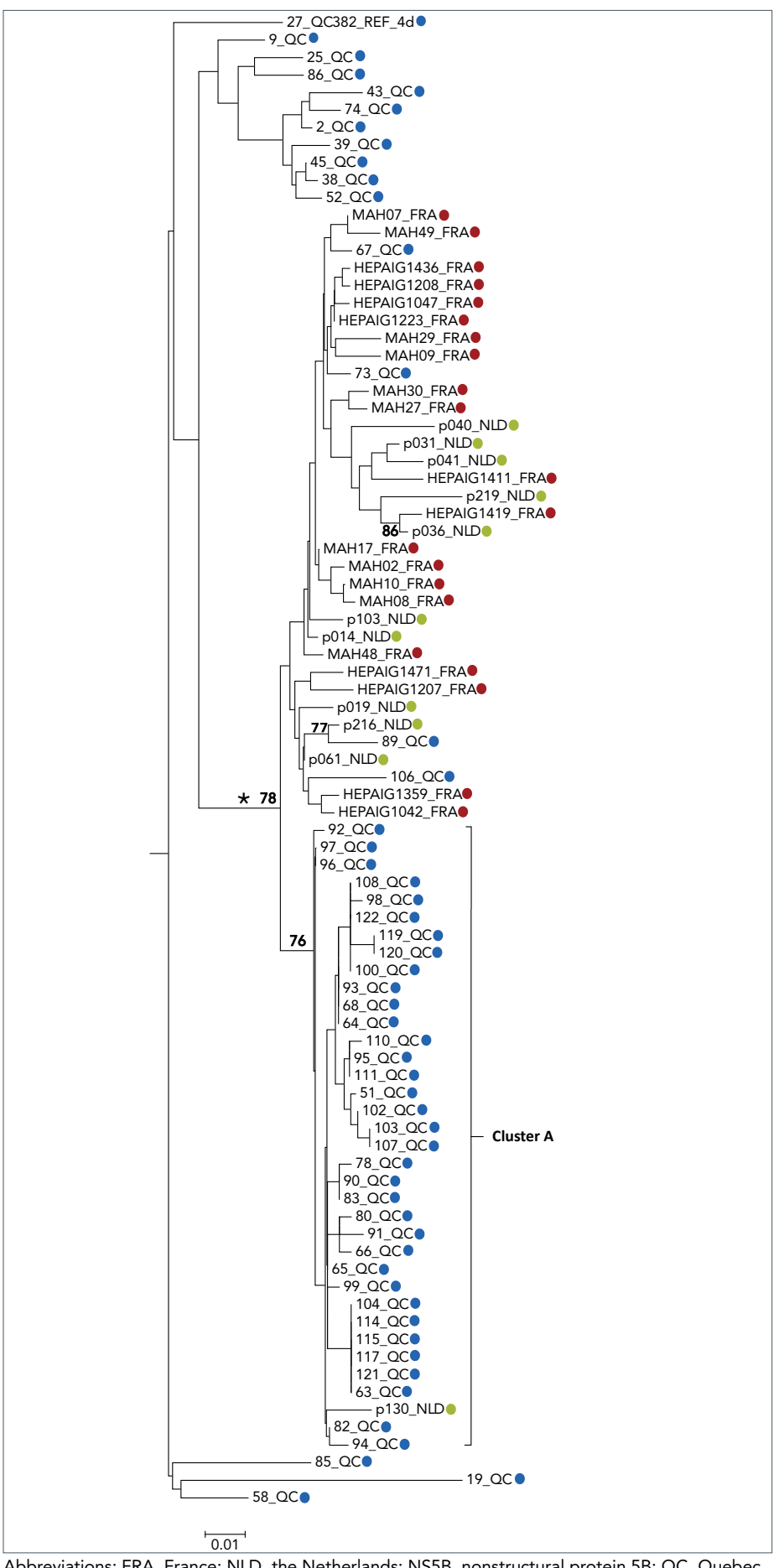

Abbreviations: FRA, France; NLD, the Netherlands; NS5B, nonstructural protein 5B; QC, Quebec Legend:

Tree inferred from NS5B sequences corresponding to nucleotide positions 8276-8615

Blue, Quebec; red, France; green, the Netherlands

Numbers at nodes represent the percent bootstrap values (only values greater than $70 \%$ are

shown on nodes of non-identical sequences)

The cross-continental G4d monophyletic lineage is indicated by an asterisk

Source: Laboratoire de santé publique du Québec, December 2018 and references 23-25
Figure A2: Phylogenetic tree of genotype 4d NS5B hepatitis $C$ virus isolate sequences: cases in Quebec compared to cases in England, France, Germany and the Netherlands

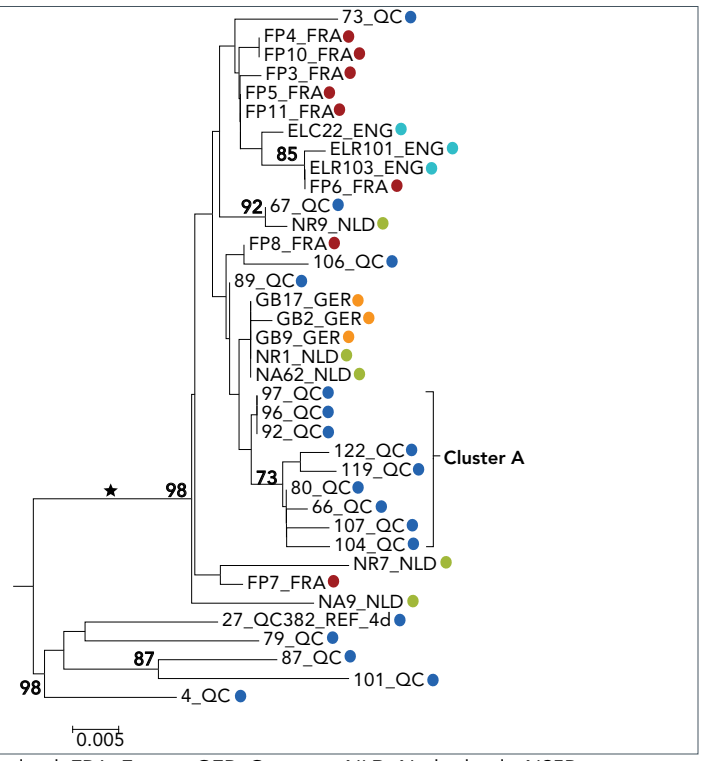

Abbreviations: ENG, England; FRA, France; GER, Germany; NLD, Netherlands; NS5B , nonstructural protein 5B; QC, Quebec

Legend:

Tree inferred from NS5B sequences corresponding to nucleotide positions 8547-8982

Blue, Quebec; red, France; green, the Netherlands; turquoise England; orange Germany Numbers at nodes represent the percent bootstrap values (only values greater than $70 \%$ are shown on nodes of non-identical sequences)

The cross-continental G4d monophyletic lineage is indicated by an asterisk

Source: Laboratoire de sante publique du Quebec, December 2018 and reference 20 